\title{
Dermatology
}

Dermatology 2017;233:314-319

DOI: $10.1159 / 000484168$
Received: July 27, 2017

Accepted after revision: October 10, 2017

Published online: December 1, 2017

\section{Suppressed Adiponectin Levels and Increased Adiponectin Response to Oral Glucose Load in Lean Women with Severe Acne Normalizes after Isotretinoin Treatment}

\author{
Kadriye Aydin ${ }^{a}$ Fatma Çetinözman $^{b}$ Gonca Elcin $^{b}$ Duygu Yazgan Aksoy ${ }^{d}$ \\ Fatma Ucarc Bulent O. Yildiz ${ }^{\mathrm{a}}$ \\ ${ }^{a}$ Division of Endocrinology and Metabolism, Department of Internal Medicine, and ${ }^{\mathrm{b}}$ Department of Dermatology \\ and Venereal Diseases, Hacettepe University School of Medicine, and ' Department of Biochemistry, Dışkapı \\ Research and Training Hospital, Ankara, and ${ }^{\mathrm{d}}$ Department of Endocrinology and Metabolism, Acıbadem University \\ School of Medicine, Istanbul, Turkey
}

\section{Keywords}

Severe acne · Adiponectin · Isotretinoin · Insulin resista

\begin{abstract}
Background/Aim: Isotretinoin, the drug of choice for severe acne, might be associated with a decrease in insulin sensitivity. Adiponectin is an adipose tissue-derived protein that increases insulin sensitivity. In this study, we aimed to investigate adiponectin levels in postadolescent severe acne and the effect of isotretinoin on adiponectin levels. Methods: Participants included 18 female patients with severe acne and 18 healthy women matched for age and body mass index (BMI). Acne patients completed a 6-month isotretinoin treatment. Anthropometric measurements, serum adiponectin, lipids, fasting glucose, fasting insulin, and homeostatic model assessment for insulin resistance (HOMA-IR) were determined, and a standard 2-h oral glucose tolerance test (OGTT) was performed in healthy women once and in patients with acne before and after treatment. Results: At baseline, patients with acne had significantly lower serum adiponectin levels than controls. Isotretinoin treatment resulted in a significant increase in weight, BMI, and triglycer-
\end{abstract}

\section{KARGER}

E-Mail karger@karger.com

www.karger.com/drm ide and adiponectin levels. Glucose metabolism markers in patients with acne and controls were similar at baseline and did not change after treatment. Baseline OGTT in acne patients revealed an increased adiponectin response at $2 \mathrm{~h}$, which was not present in healthy controls. Remarkably, this OGTT-induced adiponectin increment in acne patients was diminished after isotretinoin treatment. Conclusion: Adiponectin levels are differently regulated in women with severe acne and healthy controls in that circulating basal levels in patients are suppressed and show an increase in response to oral glucose load. Suppression of baseline adiponectin ameliorates after 6 months of isotretinoin treatment, reaching levels similar to those of healthy controls.

(C) 2017 S. Karger AG, Basel

\section{Introduction}

Acne is a chronic inflammatory disease of the pilosebaceous unit with multifactorial pathogenesis and is associated with insulin resistance [1-3]. Isotretinoin is a derivative of vitamin $\mathrm{A}$, collectively named retinoids, that is currently the most effective treatment for severe acne [4- 


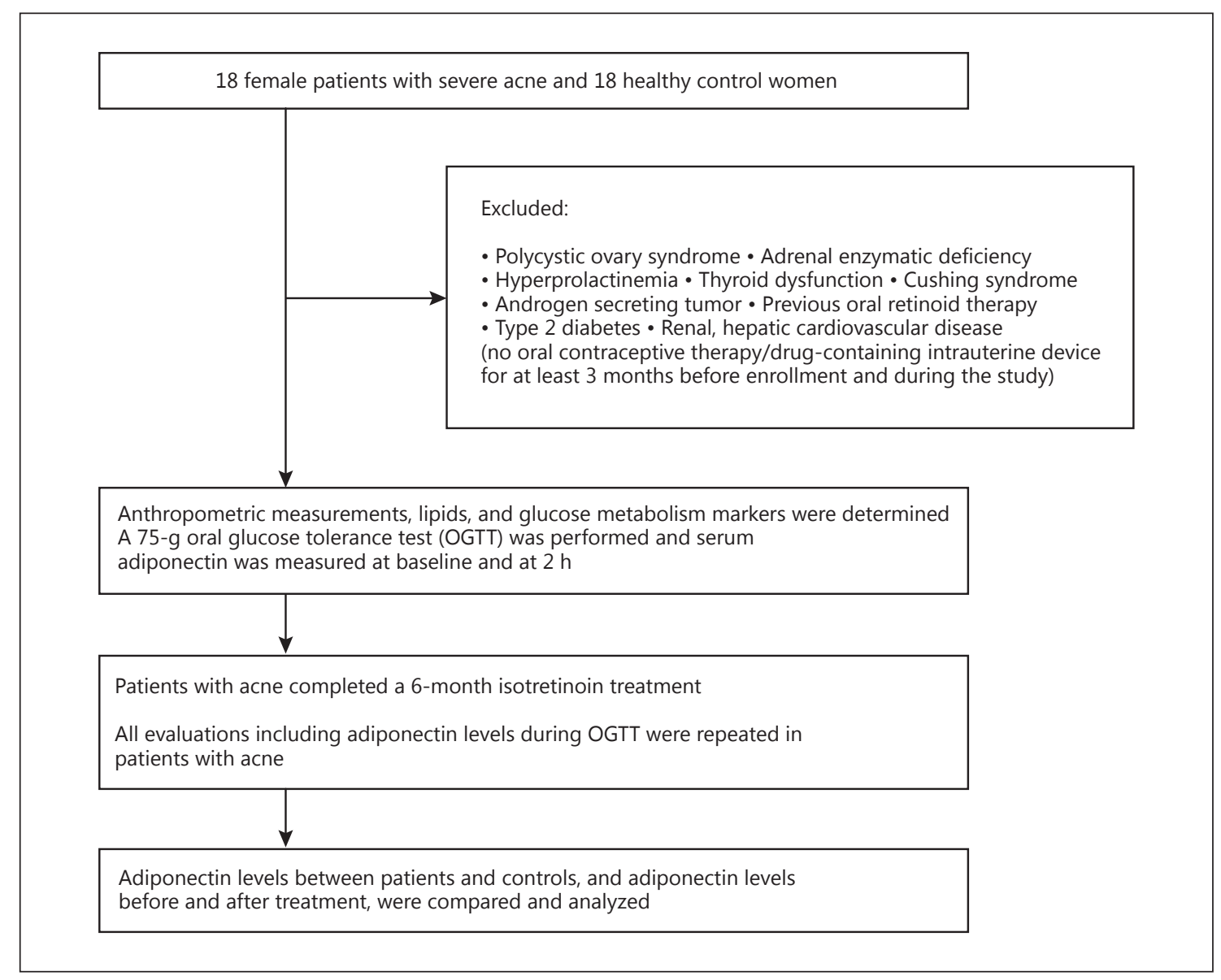

Fig. 1. Flowchart of Materials and Methods.

6]. Isotretinoin therapy may be associated with metabolic disturbances $[7,8]$.

Adipose tissue is a major site of storage for vitamin A derivatives and plays an active role in their homeostasis and metabolism [9]. Adiponectin is an adipose tissue-derived adipocytokine associated with insulin sensitivity $[10,11]$. Circulating adiponectin concentrations are reduced in insulin-resistant states such as coronary artery disease, hypertension, metabolic syndrome, or type 2 diabetes [12]. Adiponectin concentrations are also significantly lower in obese than in non-obese subjects despite extensive production of adiponectin retinoids in adipose tissue [13]. Adiponectin has been shown to reverse insulin resistance associated with lipoatrophy and obesity in animal studies [14]. A reduction in adiponectin levels precedes a reduction in insulin sensitivity, and humans with low plasma adiponectin concentration tend to become insulin-resistant years later [15]. Limited data on

Acne, Isotretinoin, and Adiponectin Relation adiponectin levels in acne patients are available from a few studies that have assessed adiponectin levels before and after treatment with isotretinoin $[16,17]$. Basal adiponectin levels and adiponectin response to a standardized oral glucose tolerance test (OGTT) have not yet been investigated in patients with acne in comparison to healthy women.

In the present study, we aimed to analyze whether the level of adiponectin is different in female patients with postadolescent severe acne compared to healthy women and whether isotretinoin treatment affects adiponectin levels in relation to insulin resistance in those patients.

\section{Materials and Methods}

For further details, see the online supplementary material (www.karger.com/doi/10.1159/000484168) [18-24] (Fig. 1). 
Fig. 2. Adiponectin responses to the oral glucose tolerance test in controls and patients.

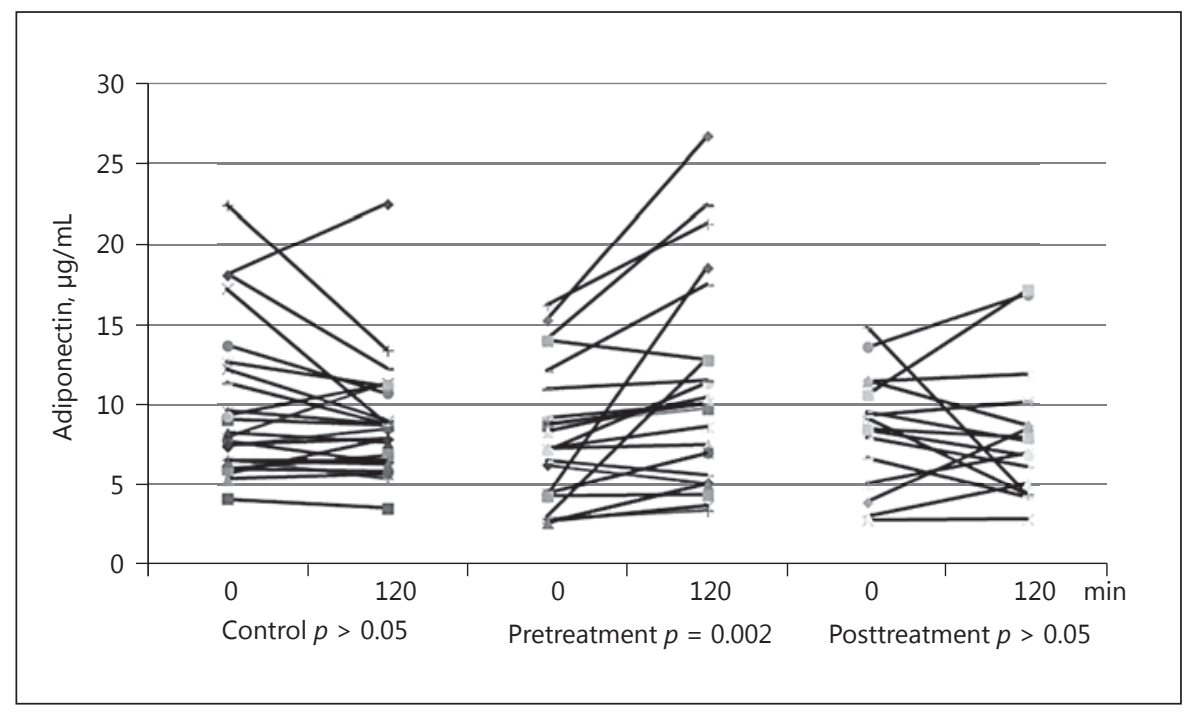

Table 1. Clinical, hormonal, and biochemical characteristics of all participants at baseline and of women with severe acne after treatment

\begin{tabular}{|c|c|c|c|c|c|}
\hline & $\begin{array}{l}\text { Controls } \\
(n=18)\end{array}$ & $\begin{array}{l}\text { Patients } \\
(n=18)\end{array}$ & $\begin{array}{l}\text { Patients }-6 \text { th month } \\
(n=18)\end{array}$ & $\begin{array}{l}p \text { value }^{\mathrm{a}} \\
\text { (acne-control) }\end{array}$ & $\begin{array}{l}p \text { value }^{\mathrm{b}} \\
\text { (pre-post) }\end{array}$ \\
\hline Age, years & $24.4 \pm 2.4$ & $23.4 \pm 3.4$ & & 0.161 & \\
\hline Weight, kg & $56.2 \pm 7.8$ & $57.6 \pm 8.5$ & $59.7 \pm 9.8$ & 0.602 & 0.010 \\
\hline $\mathrm{BMI}$ & $20.7 \pm 2.5$ & $20.5 \pm 2.1$ & $21.2 \pm 2.7$ & 0.748 & 0.010 \\
\hline Waist, cm & $72.0 \pm 7.7$ & $74.3 \pm 7.4$ & $76.2 \pm 7.3$ & 0.363 & 0.218 \\
\hline WHR & $0.77 \pm 0.06$ & $0.80 \pm 0.05$ & $0.80 \pm 0.06$ & 0.132 & 0.605 \\
\hline \multicolumn{6}{|l|}{ IR and glucose metabolism } \\
\hline Fasting glucose, mg/dL & $85.6 \pm 8.9$ & $85.7 \pm 16.8$ & $80.7 \pm 13.9$ & 0.980 & 0.463 \\
\hline Insulin, $\mu \mathrm{IU} / \mathrm{mL}$ & $8.5 \pm 3.6$ & $10.3 \pm 3.3$ & $11.8 \pm 4.5$ & 0.127 & 0.286 \\
\hline HOMA-IR & $1.8 \pm 0.8$ & $2.2 \pm 0.7$ & $2.4 \pm 1.1$ & 0.182 & 0.286 \\
\hline Adiponectin $0, \mu \mathrm{g} / \mathrm{mL}$ & $10.9 \pm 5.2$ & $6.5 \pm 3.8$ & $8.7 \pm 3.4$ & 0.006 & 0.031 \\
\hline Adiponectin $120, \mu \mathrm{g} / \mathrm{mL}$ & $9.4 \pm 4.1$ & $9.5 \pm 5.5$ & $8.2 \pm 4.0$ & 0.591 & 0.306 \\
\hline \multicolumn{6}{|l|}{ Lipids, mg/dL } \\
\hline Total cholesterol & $162.6 \pm 25.9$ & $156.1 \pm 29.5$ & $159.8 \pm 26.3$ & 0.484 & 0.248 \\
\hline $\mathrm{TG}$ & $66.3 \pm 29.9$ & $77.1 \pm 27.7$ & $101.6 \pm 39.7$ & 0.270 & 0.003 \\
\hline LDL-C & $86.3 \pm 21.0$ & $82.5 \pm 22.7$ & $88.8 \pm 23.4$ & 0.603 & 0.157 \\
\hline HDL-C & $61.5 \pm 12.1$ & $56.2 \pm 12.7$ & $55.9 \pm 14.4$ & 0.209 & 0.931 \\
\hline
\end{tabular}

WHR, waist-to-hip ratio; IR, insulin resistance; HOMA-IR, homeostasis model assessment for insulin resistance; TG, triglycerides; LDL-C, low-density lipoprotein cholesterol; HDL-C, high-density lipoprotein cholesterol. ${ }^{\text {a }}$ For baseline assessment of acne patients and control group. ${ }^{b}$ For assessment of pre- and posttreatment features of acne patients.

\section{Results}

We found that basal adiponectin levels of patients with acne were significantly lower than the basal adiponectin levels of the control subjects $(p=0.006)$. After 6 months of treatment with isotretinoin, basal adiponectin levels significantly increased $(p=0.031)$. Remarkably, when pa- tients with acne were subjected to the OGTT at baseline, we found that the adiponectin levels showed a significant increase at the 2 -h time point $(p=0.002)$, reaching similar adiponectin levels to those found in healthy subjects. However, this glucose-induced increment in adiponectin levels was lost in the patients after isotretinoin treatment $(p=0.711)$. The OGTT had no effect on the serum adipo- 
nectin levels in healthy controls $(p=0.112)$. Adiponectin dynamics during OGTT are shown in Figure 2.

Insulin sensitivity markers and lipids were similar in patients with acne and healthy controls at baseline, and insulin sensitivity markers did not change significantly after isotretinoin treatment, as previously reported (Table 1) [18].

Correlation analyses showed that adiponectin was negatively correlated with homeostatic model assessment for insulin resistance (HOMA-IR) and basal insulin in patients with acne $(p=0.001, r=-0.731$ and $p=0.008$, $r=-0.607$, respectively), but not in controls. However, after isotretinoin treatment, the correlation of adiponectin with HOMA-IR and basal insulin was diminished. Adiponectin levels at $2 \mathrm{~h}$ during OGTT were not correlated with glucose and insulin levels at the same time point. Adiponectin levels at baseline showed no correlation with any of the lipid parameters in patients, and adiponectin was positively correlated with HDL-C in controls $(p=0.019, r=0.548)$. As triglyceride levels increased after treatment, we made a correlation analysis between the change in triglycerides and the change in adiponectin levels, but could not detect a correlation between them.

\section{Discussion}

Oral isotretinoin is the revolutionary drug in the treatment of severe acne, but it has some undesired metabolic side effects [8]. Adiponectin metabolism is complex, but it is generally accepted that it is reduced in conditions with increased adiposity, atherosclerosis, and insulin resistance, and that it has beneficial effects on insulin action and lipid metabolism [19]. In the present study, we showed that basal adiponectin levels in female patients with postadolescent severe acne were lower than those in healthy women matched for age and body mass index (BMI), while upon treatment with isotretinoin for 6 months these patients showed increased adiponectin levels without a significant effect on glucose metabolism markers. In addition, isotretinoin treatment restored dysregulation of adiponectin dynamics after glucose load in patients with severe acne.

The number of reports on serum adiponectin levels in acne patients is limited. Koistinen et al. [16] investigated 11 men with acne (age 24.2 \pm 2 years, BMI $22.1 \pm$ 0.9 ) and described a paradoxical rise in serum adiponectin levels after isotretinoin treatment for approximately 5 months, which returned to pretreatment levels 1 month after the end of therapy. They demonstrated a reversible

Acne, Isotretinoin, and Adiponectin

Relation reduction in insulin sensitivity during treatment by the euglycemic hyperinsulinemic clamp technique. Unfortunately, a healthy control group was not included in this study. A similar increase in adiponectin concentrations was found by Heliövaara et al. [17], who evaluated 23 patients with acne ( 11 female, 12 male; age $24.9 \pm 0.9$ years; BMI $22.6 \pm 0.7$ ) before, after a 3-month treatment with isotretinoin, and 1 month after treatment cessation, using a 4-h OGTT. The individual fasting glucose and insulin levels and the area under the curve for glucose and insulin during the 4-h OGTT were unchanged during the different phases of the study. In contrast to these studies, Corbetta et al. [20] found that adiponectin levels remained unchanged during a 1-month treatment period and after cessation of treatment when evaluating the effect of retinoid derivative acitretin in patients with psoriasis. However, this distinct result may be related to the application of a different drug or the relatively short period of treatment. Our study has some similarities and some differences with these studies regarding the study population, design, and outcomes. We included a wellcharacterized cohort of women with postadolescent severe acne, excluding obese patients and men. Our observation that serum adiponectin levels are significantly increased during isotretinoin treatment is in accordance with the results of the studies by Koistinen et al. [16] and Heliövaara et al. [17]. As we included healthy controls in our study, we were able to make the unique observation that patients with severe acne showed significantly lower basal serum adiponectin levels in comparison to nonacne healthy controls. We also observed that the phenomenon of OGTT-induced augmentation of adiponectin levels in acne patients was abrogated upon isotretinoin treatment. Moreover, isotretinoin treatment led to normalization of adiponectin levels that became nonresponsive to high glucose intake, similarly as found in healthy controls.

Adiponectin is known to be decreased in insulin resistant conditions such as obesity and diabetes [19]. In our study, at the level of similar glycemia and insulin sensitivity to healthy controls, lean women with acne had suppressed adiponectin levels. Acne is regarded as a chronic inflammatory disease, and biopsies of the inflammatory acne lesions revealed the expression of proinflammatory factors [21]. In in vitro studies, proinflammatory factors including cytokines such as TNF- $\alpha$ and IL- 6 suppress adiponectin production by adipocytes [22,23]. Based on the fact that sebocytes resemble adipocytes in linking lipid metabolism with inflammatory activity, Kovacs et al. [24] analyzed the expression of various adipocytokines, including adiponectin, in sebaceous glands. They showed

Dermatology 2017;233:314-319

DOI: 10.1159/000484168 
that, similar to adipocytes, sebocytes differentially express and secrete adipokines and that expression of them could be regulated by various stimuli including isotretinoin. The study by Kovacs et al. [24] supports our findings in part that adiponectin is associated with severe acne and isotretinoin is able to modulate adiponectin. Jung et al. [25] specifically evaluated adiponectin signaling in sebaceous glands and demonstrated that human sebaceous glands in vivo and sebocytes in vitro expressed adiponectin receptors. They stated that adiponectin strongly upregulated lipid production in sebocytes. The cumulative data so far identifies sebaceous glands as potential sources of adipocytokines [26].

An interesting point in our study is that the basal adiponectin level increased after isotretinoin despite the fact that there was an increase in body weight and triglyceride level even though insulin sensitivity remained the same. This finding suggests that isotretinoin either shows a direct effect on the synthesis and secretion of adiponectin or indirectly affects the adiponectin levels by improvement of the proinflammatory state observed in acne. Since isotretinoin modifies the inflammation of the acne lesions, the suppressive effect of these cytokines on adiponectin expression may be reversed by isotretinoin. Alternatively, a direct effect of isotretinoin may occur through its receptor interactions. Retinoids exert their function through the retinoic acid receptor (RAR) and the retinoid X receptor (RXR), which is the obligate partner for peroxisome proliferator-activated receptor- $\gamma$ (PPAR $\gamma)$ [27-29]. After binding, the PPAR $\gamma$-RXR heterodimer activates the human adiponectin promoter, leading to increased adiponectin in response to PPAR $\gamma$ triggering [30].

Regarding the association of adiponectin and insulin sensitivity, adiponectin dynamics during OGTT may have a role in postprandial glucose. In the studies evaluating the response of adiponectin to acute hyperglycemia during OGTT, adiponectin levels were not changed $2 \mathrm{~h}$ after glucose load in insulin-sensitive slim probands [31], as well as in normal glucose-tolerant, impaired glucosetolerant, and type 2 diabetic probands [32], whereas an increase in adiponectin levels was observed in patients with polycystic ovary syndrome [33]. In the present study we detected an increased adiponectin response to oral glucose at $2 \mathrm{~h}$ during OGTT which was not present in nonacne healthy controls and was diminished after isotretinoin therapy. As adiponectin levels do not change in response to oral glucose load in healthy women [3436], we do not expect a rise of adiponectin during OGTT. It appears that isotretinoin treatment restores dysregula-

318

Dermatology 2017;233:314-319

DOI: $10.1159 / 000484168$ tion of adiponectin dynamics in severe acne. Adiponectin is found to be positively correlated with HDL-C and inversely correlated with triglycerides in healthy people [36]. In our study, no correlation of adiponectin with lipids in patients with acne also suggests dysregulation of adiponectin in patients with severe acne. In contrast to the study by Heliövaara et al. [17], we did not detect a correlation between the change in triglycerides and the change in adiponectin levels.

Limitations of our study include the relatively small sample size and the observational design. We included only lean women with severe acne, and caution should be taken to extrapolate our results to obese or male patients or patients with milder forms of acne.

In conclusion, adiponectin levels are differently regulated in women with severe acne compared to healthy controls in that circulating basal levels are suppressed and show an increase in response to oral glucose load. Suppression of baseline adiponectin ameliorates after 6 months of isotretinoin treatment, reaching levels similar to those of healthy controls.

\section{Key Message}

Adiponectin is differently regulated in women with severe acne, and isotretinoin restores adiponectin dynamics.

\section{Statement of Ethics}

This was a prospective observational study approved by the institutional review board of the Hacettepe University Medical Faculty.

\section{Disclosure Statement}

None of the authors have any conflicts of interest to disclose.

References

1 Williams HC, Dellavalle RP, Garner S: Acne vulgaris. Lancet 2012;379:361-372.

2 Ottaviani M, Camera E, Picardo M: Lipid mediators in acne. Mediators Inflamm 2010; 2010:858176.

3 Del Prete M, Mauriello MC, Faggiano A, Di Somma C, Monfrecola G, Fabbrocini G, Colao A: Insulin resistance and acne: a new risk factor for men? Endocrine 2012;42:555-560.

4 Peck GL, Olsen TG, Yoder FW, Strauss JS, Downing DT, Pandya M, Butkus D, ArnaudBattandier J: Prolonged remissions of cystic and conglobate acne with 13-cis-retinoic acid. N Engl J Med 1979;300:329-333.

Aydin/Çetinözman/Elcin/Aksoy/Ucar/ Yildiz 
5 Strauss JS, Rapini RP, Shalita AR, Konecky E, Pochi PE, Comite H, Exner JH: Isotretinoin therapy for acne: results of a multicenter dose-response study. J Am Acad Dermatol 1984;10:490-496.

6 Strauss JS, Krowchuk DP, Leyden JJ, Lucky AW, Shalita AR, Siegfried EC, Thiboutot DM, Van Voorhees AS, Beutner KA, Sieck CK, Bhushan R, American Academy of Dermatology/American Academy of Dermatology: Guidelines of care for acne vulgaris management. J Am Acad Dermatol 2007;56:651-663.

7 Lyons F, Laker MF, Marsden JR, Manuel R, Shuster S: Effect of oral 13-cis-retinoic acid on serum lipids. Br J Dermatol 1982;107:591595.

8 Koistinen HA, Remitz A, Gylling H, Miettinen TA, Koivisto VA, Ebeling P: Dyslipidemia and a reversible decrease in insulin sensitivity induced by therapy with 13-cis-retinoic acid. Diabetes Metab Res Rev 2001;17:391-395.

9 Bonet ML, Ribot J, Felipe F, Palou A: Vitamin $\mathrm{A}$ and the regulation of fat reserves. Cell Mol Life Sci 2003;60:1311-1321.

10 Fantuzzi G: Adiponectin and inflammation: consensus and controversy. J Allergy Clin Immunol 2008;121:326-330.

11 Weyer C, Funahashi T, Tanaka S, Hotta K, Matsuzawa Y, Pratley RE, Tataranni PA: Hypoadiponectinemia in obesity and type 2 diabetes: close association with insulin resistance and hyperinsulinemia. J Clin Endocrinol Metab 2001;86:1930-1935.

12 Kadowaki T, Yamauchi T: Adiponectin and adiponectin receptors. Endocr Rev 2005;26: 439-451.

13 Arita Y, Kihara S, Ouchi N, Takahashi M, Maeda K, Miyagawa J, Hotta K, Shimomura I, Nakamura T, Miyaoka K, Kuriyama H, Nishida M, Yamashita S, Okubo K, Matsubara K, Muraguchi M, Ohmoto Y, Funahashi T, Matsuzawa Y: Paradoxical decrease of an adiposespecific protein, adiponectin, in obesity. Biochem Biophys Res Commun 1999;257:79-83.

14 Yamauchi T, Kamon J, Waki H, Terauchi Y, Kubota N, Hara K, Mori Y, Ide T, Murakami K, Tsuboyama-Kasaoka N, Ezaki O, Akanuma Y, Gavrilova O, Vinson C, Reitman ML, Kagechika H, Shudo K, Yoda M, Nakano Y, Tobe K, Nagai R, Kimura S, Tomita M, Froguel P, Kadowaki T: The fat-derived hormone adiponectin reverses insulin resistance associated with both lipoatrophy and obesity. Nat Med 2001;7:941-946.
15 Stefan N, Vozarova B, Funahashi T, Matsuzawa Y, Weyer C, Lindsay RS, Youngren JF, Havel PJ, Pratley RE, Bogardus C, Tataranni PA: Plasma adiponectin concentration is associated with skeletal muscle insulin receptor tyrosine phosphorylation, and low plasma concentration precedes a decrease in wholebody insulin sensitivity in humans. Diabetes 2002;51:1884-1888.

16 Koistinen HA, Remitz A, Koivisto VA, Ebeling P: Paradoxical rise in serum adiponectin concentration in the face of acid-induced insulin resistance 13-cis-retinoic. Diabetologia 2006;49:383-386.

17 Heliövaara MK, Remitz A, Reitamo S, Teppo AM, Karonen SL, Ebeling P: 13-cis-retinoic acid therapy induces insulin resistance, regulates inflammatory parameters, and paradoxically increases serum adiponectin concentration. Metabolism 2007;56:786-791.

18 Cetinozman F, Aksoy DY, Elcin G, Yildiz BO: Insulin sensitivity, androgens and isotretinoin therapy in women with severe acne. J Dermatolog Treat 2014;25:119-122.

19 Galic S, Oakhill JS, Steinberg GR: Adipose tissue as an endocrine organ. Mol Cell Endocrinol 2010;316:129-139.

20 Corbetta S, Angioni R, Cattaneo A, Beck-Pec$\operatorname{coz}$ P, Spada A: Effects of retinoid therapy on insulin sensitivity, lipid profile and circulating adipocytokines. Eur J Endocrinol 2006; 154:83-86.

21 Ingham E, Eady EA, Goodwin CE, Cove JH, Cunliffe WJ: Pro-inflammatory levels of interleukin-1 alpha-like bioactivity are present in the majority of open comedones in acne vulgaris. J Invest Dermatol 1992;98:895-901.

22 Ouchi N, Walsh K: Adiponectin as an antiinflammatory factor. Clin Chim Acta 2007; 380:24-30.

23 Ohashi K, Kihara S, Ouchi N, Kumada M, Fujita K, Hiuge A, Hibuse T, Ryo M, Nishizawa H, Maeda N, Maeda K, Shibata R, Walsh K, Funahashi T, Shimomura I: Adiponectin replenishment ameliorates obesity-related hypertension. Hypertension 2006; 47:11081116.

24 Kovacs D, Lovaszi M, Poliska S, Olah A, Biro T, Veres I, Zouboulis CC, Stahle M, Ruhl R, Remenyik E, Torocsik D: Sebocytes differentially express and secrete adipokines. Exp Dermatol 2016;25:194-199.

25 Jung YR, Lee JH, Sohn KC, Lee Y, Seo YJ, Kim CD, Lee JH, Hong SP, Seo SJ, Kim SJ, Im M: Adiponectin signaling regulates lipid production in human sebocytes. PLoS One 2017; 12:e0169824.
26 Zouboulis CC, Picardo M, Ju Q, Kurokawa I, Torocsik D, Biro T, Schneider MR: Beyond acne: current aspects of sebaceous gland biology and function. Rev Endocr Metab Disord 2016;17:319-334

27 Villarroya F, Giralt M, Iglesias R: Retinoids and adipose tissues: metabolism, cell differentiation and gene expression. Int J Obes Relat Metab Disord 1999;23:1-6.

28 Desvergne B, Wahli W: Peroxisome proliferator-activated receptors: nuclear control of metabolism. Endocr Rev 1999;20:649-688.

29 Bardot O, Aldridge TC, Latruffe N, Green S: PPAR-RXR heterodimer activates a peroxisome proliferator response element upstream of the bifunctional enzyme gene. Biochem Biophys Res Commun 1993;192:37-45.

30 Iwaki M, Matsuda M, Maeda N, Funahashi T, Matsuzawa Y, Makishima M, Shimomura I: Induction of adiponectin, a fat-derived antidiabetic and antiatherogenic factor, by nuclear receptors. Diabetes 2003;52:1655-1663.

31 Friedewald WT, Levy RI, Fredrickson DS: Estimation of the concentration of low-density lipoprotein cholesterol in plasma, without use of the preparative ultracentrifuge. Clin Chem 1972;18:499-502.

32 Osei K, Gaillard T, Schuster D: Plasma adiponectin levels in high risk African-Americans with normal glucose tolerance, impaired glucose tolerance, and type 2 diabetes. Obes Res 2005; 13:179-185.

33 Lewandowski KC, Szosland K, O'Callaghan C, Tan BK, Randeva HS, Lewinski A: Adiponectin and resistin serum levels in women with polycystic ovary syndrome during oral glucose tolerance test: a significant reciprocal correlation between adiponectin and resistin independent of insulin resistance indices. Mol Genet Metab 2005;85:61-69.

34 Unluturk U, Harmanci A, Yildiz BO, Bayrak$\operatorname{tar}$ M: Dynamics of Nampt/visfatin and high molecular weight adiponectin in response to oral glucose load in obese and lean women. Clin Endocrinol 2010;72:469-474.

35 Martinez-Garcia MA, Montes-Nieto R, Fernandez-Duran E, Insenser M, Luque-Ramirez M, Escobar-Morreale HF: Evidence for masculinization of adipokine gene expression in visceral and subcutaneous adipose tissue of obese women with polycystic ovary syndrome (PCOS). J Clin Endocrinol Metab 2013;98:E388-E396.

36 Heliövaara MK, Strandberg TE, Karonen SL, Ebeling P: Association of serum adiponectin concentration to lipid and glucose metabolism in healthy humans. Horm Metab Res 2006;38:336-340.
Acne, Isotretinoin, and Adiponectin

Relation
Dermatology 2017;233:314-319

DOI: $10.1159 / 000484168$ 